\title{
Improving knowledge about diabetes among diabetic population of Gujarat, India: A community based Interventional study
}

\author{
Sandul Yasobant ${ }^{1 *}$, Nilesh Thube ${ }^{1}$, Deepak Saxena ${ }^{1}$, Sushil Patel ${ }^{2}$ and Mayur Patel ${ }^{3}$ \\ ${ }^{1}$ Indian Instititue of Public Health Gandhinagar, India \\ ${ }^{2}$ Akshar Diabetes Centre, Vadodara, Gujarat, India \\ ${ }^{3}$ All India Institute of Diabetes \& Research, Ahmedabad, India
}

\begin{abstract}
Background: Diabetes mellitus (DM) is recognized as an important cause of premature death and disability globally. In India, about 50.9 million people suffer from diabetes and this figure is likely to go upto 80 million by 2025, making it the "Diabetic Capital" of the world. Evidences signposts that appropriate health education program could improve the knowledge of diabetic patients and change their attitude. Therefore, this study aims to document the baseline knowledge about diabetes; followed which an intervention and change in knowledge level among Type-2 diabetes patients in Gujarat, India.

Methods: This is a multi-centric prospective study with a phase of intervention among the diabetic patients in three diverse districts Mehsana (Rural), Chota Udaipur (Tribal), Ahmedabad (Urban) of Gujarat, India. A pre-tested pilot validated questionnaire in vernacular language has been administered to 713 and 577 Type-2 diabetic patients in baseline and endline respectively. Data on knowledge about diabetes causes, symptoms, complications, management practices were collected. Data were entered and monitored in Epi Info 7 and analyzed by IBM SPSS 20 software.
\end{abstract}

Result: Baseline knowledge about diabetes causes, symptoms and complications found to be poor in this study. Change in knowledge and improved practices were revealed in endline survey because of an appropriate intervention program.

Conclusion: This study found that the knowledge and practices about management of diabetes could be changed with suitable designed community based intervention programs.

\section{Introduction}

Diabetes mellitus (DM) is a major emerging challenge for public health not only for developed nations but also for Low-Middle Income countries (LMIC) like India [1,2]. Worldwide about 170 million people are living with diabetes; further, researchers have predicted a $65 \%$ rise in the prevalence of diabetes owing to the population growth rate, age structure, urbanization, unfavorably modification of dietary habits and lifestyles, economic and health transition of the country [3]. According to the recent projections of World Health Organization (WHO), India already leads the world with the largest number of diabetic subjects (nearly 40 million) and it is predicted that this number would reach almost 80 million by the year 2030 [4]. As India is the "Diabetic Capital" and majority of the people with diabetes in are within the productive age range of 45-64 years [1,5].

Studies in India estimate that, for a low-income Indian family with an adult with diabetes, as much as $25 \%$ of family income may be devoted to diabetes care. Intangible costs (pain, anxiety, inconvenience and generally lower quality of life etc.) also have great impact on the lives of patients and their families and are the most difficult to quantify $[6,7]$. The reasons for the increase in the prevalence of diabetes mellitus in developing countries may include unhealthy lifestyle, rapid westernization, poor knowledge, negative attitude and poor practices towards DM among the general population $[8,9]$. There exists a large gap between the knowledge, attitude and practice towards diabetes among diabetic patients $[10,11]$. Knowledge about diabetes mellitus, appropriate attitude and practices are vital to reduce the prevalence and morbidity associated with DM. However, very few studies focused on this area and there is also lack of data on knowledge \& practices among Indian diabetic patients. [12]. Recent surveys indicate that diabetes now affects a staggering $10-16 \%$ of urban population and (5$8 \%$ ) of rural population in India [13,14]. There is very little data on the level of awareness about diabetes in developing countries like India.

Despite differences in individual needs to cope with diabetes, there is general agreement for the necessity of supportive programs for patient self-management. While traditional programs were didactic models with the goal of improving patients' knowledge of their disease, current models focus on behavioral approaches aimed at providing

Correspondence to: Dr. Sandul Yasobant, Indian Institute of Public Health Gandhinagar, Palaj Village, Lekawada Cross Road, Opp. Air Force Head Quarter Main Gate, Chiloda Road, Gandhinagar-382355, Tel: 092280100200, +919662251905, E-mail: yasobant@iiphg.org

Key words: type-2 Diabetes, knowledge, intervention, Gujarat

Received: August 03, 2016; Accepted: September 15, 2016; Published: October 29, 2016 
patients with the skills and strategies required to promote and change their behavior [15]. Evidences indicates that a proper education and awareness program can change the attitude of the public regarding diabetes, as a large gap between knowledge and attitude among the diabetes patients was found and proper knowledge regarding various aspects of health education program can improve the knowledge of patients and change their attitude [5].

Our initial aim was to assess baseline levels of knowledge, attitudes, and some aspects of self-management of diabetes care in a representative sample of urban, tribal, rural population with Type 2 diabetes in Gujarat. Then we used the baseline results to help develop a culturally appropriate (competent) educational intervention programme for these groups. We then investigated whether this intervention could produce an improvement, and finally whether any improvement was greater than background changes in knowledge or not.

\section{Methods}

\section{Study type}

This is a multi-centric prospective study with a phase of intervention among the diabetic patients in general community. This study has three phases i.e. baseline to gather knowledge about DM among diabetes patients, followed by an appropriate intervention and finally endline to document the changes in knowledge.

\section{Study setting}

This study has been conducted in three diverse districts (Mehsana, Chota Udaipur, Ahmedabad) of Gujarat, India. Gujarat is the western state of the India, bordered states by Madhya Pradesh to the east, Maharashtra to the south and Rajasthan to the north and Arabian Sea \& Sindh province of Pakistan to the west. Gujarat is one of the most industrialized states of India with 66.3 million populations in year 2016. It includes 33 districts and population is distributed in urban, rural and tribal areas. As per census data 2011, Mehsana district population has been increased 2,027,727 Crore [16]. Ahmedabad is the leading district of state in terms of population and holding largest population 7,208,200 Crore and Chota Udaipur district includes 1,071,831 Crore population $[17,18]$.

\section{Study sample}

Though the study by design is a prospective study, the baseline \& endline sampling was done based on population proportion to sample size. The sample subjects were selected by systematic random sampling technique from known cases of diabetes in study areas. The sample size for baseline was 713 and 577 for the endline. Assuming each of the $\mathrm{PHC}$ as a cluster, the house to house survey was conducted in PHC village till, known cases of diabetes are identified in each PHC Village (Mehsana District has 52 PHC, Chota Udaipur has 16 PHCs and Ahmedabad has 10 UHCs under the study).

\section{Study data collection method}

Written consent was obtained from the respondents after explaining the purpose of the study and reassuring him/her about the strict confidentiality of any obtained information and the study results would be used only for the research purpose without disclosing his/her names. Structured questionnaire tool was used for data collection in respective study areas. Tools were developed in English and translated into local Gujarati language. Tools were targeted for obtaining household information, measuring KAP among diabetic population. Data collection done by trained social worker students and questioners were introduced them by technical training and mock interviews. Time taken for each respondent to complete detail questioner range was between 15-20 minutes. Baseline was conducted during June 2013 and Endline during December 2014. The middle period was the time for intervention activities to improve knowledge \& practices about diabetes.

\section{Ethics}

The Study has obtained ethical clearance by Institutional Ethical Committee (IEC) of the Indian Institute of the Public Health Gandhinagar (IIPHG).

\section{Study data variables}

Data collection were done by pre-constructed and pre-tested questioner that was covered as follows,

Personal and socio-economic data (Name, sex, age, Address, marital status, education, occupation and type of physical activity. Information also obtained about total number of family members, religion, caste, source of drinking water, type of toilet facility and monthly total family income).

- Closed ended questions were asked about knowledge and practices of diabetes management and care. That was detail focused on to determine knowledge regarding symptoms, complications, treatments and prevention methods of diabetes mellitus.

- Practices towards regular exercise, diet, medication and health care accessibility for diabetes care.

Structured questioners were also tried to include, addiction habits among respondents and details information about laboratory test for diabetes management.

\section{Intervention phase}

This study has an intervention at two important levels. Initially health system level intervention such as Continuous Training Program to healthcare professionals such as Medical officers, Paramedical staffs, Educational materials such as posters, banners, pamphlets, diabetes card provided at each healthcare facility including handholding activities on Glucometer and Skype for ease of consultation. At community level interventions were done such as street play, community workshops, health camps, various vernacular IEC materials regarding diabetes prevention \& early management. During these phase there was a great advocacy done with Government, which has been published elsewhere [19].

\section{Data analysis}

Data were entered and monitored in Epi Info 7 and analyzed by IBM SPSS 20 software. Descriptive statistics were done for continuous variables in the form of mean and standard deviation, whereas proportions for categorical variables. The level of significance was considered with $\mathrm{p}<0.05$.

\section{Results and discussion}

The mean age of all respondents were $58.3 \pm 11.8$ years, with a minute difference in baseline to endline $58.4 \pm 11.8,58.2 \pm 11.7$ respectively. There were $60.9 \%$ males and half of them were belongs to back ward caste. It has been observed that about one-fourth of study sample have the habit of tobacco consumption, whereas only $3.3 \%$ found to be consuming alcohol. About $46.5 \%$ populations have an 
associated problem of hypertension along with diabetes. The details of socio-demographic characteristics have been shown in Table 1.

Knowledge about diabetes such as its causes, complications and prevention strategies among diabetic patients from the surveyed community varies from baseline to endline. Samples of baseline study were having diabetes with mean $74.1 \pm 77.1$ months whereas in endline study the mean was $60.7 \pm 70.5$ months. The various dimensions of knowledge level about diabetes causes and its prevention have been shown in Table 2 with the baseline \& endline comparison. It has been observed that the knowledge level changed in endline survey as compared to baseline significantly, especially in the prevention of diabetes. Similarly, Table 3 indicates about the practices about diabetes management and its differences during baseline to endline. Intervention indicates some change in the treatment practices, frequency of investigation carried out, depended on allopathic drugs and regularity of physical activity.

In the present study, we have sought to determine the awareness level of urban, rural and tribal diabetic patients about the disease. The strategy of this study was to understand either the intervention was effective for improving the basic knowledge of diabetes mellitus, its causes, symptoms, complications, management, treatment and practices to their own diabetic management. The previous studies from various settings throughout India indicate that the knowledge level varies from region to region [20-23]. But the specialty of this study

Table 1. Socio-demographic Characteristics of Diabetes patients ${ }^{\mathrm{a}}$ in three districts ${ }^{\mathrm{b}}$ of Gujarat $(\mathrm{N}=1290)$.

\begin{tabular}{|c|c|c|c|c|c|}
\hline Characteristics & Variables & Baseline $^{c}(n=713) \%$ & Endline $^{d}(n=577) \%$ & Total $(\mathrm{N}=1290) \%$ & $p$-Value \\
\hline \multirow[t]{2}{*}{ Gender } & Male & $456(64)$ & $330(57.2)$ & $786(60.9)$ & $0.014 *$ \\
\hline & Female & $257(36)$ & $247(42.8)$ & $504(39.1)$ & \\
\hline \multirow[t]{2}{*}{ Religion } & Hindu & $676(94.8)$ & $534(92.5)$ & $1210(93.8)$ & 0.104 \\
\hline & Non-Hindu & $37(5.2)$ & $43(7.5)$ & $80(6.2)$ & \\
\hline \multirow[t]{3}{*}{ Caste } & $\mathrm{ST} / \mathrm{SC}$ & $86(12.1)$ & $89(15.4)$ & $175(13.6)$ & 0.063 \\
\hline & OBC & $223(31.3)$ & $196(34)$ & $419(32.5)$ & \\
\hline & General & $404(56.7)$ & $292(50.6)$ & $696(54)$ & \\
\hline \multirow[t]{2}{*}{ Tobacco consumption } & Yes & $197(27.6)$ & $142(24.6)$ & $339(26.3)$ & 0.227 \\
\hline & No & $516(72.4)$ & $435(75.4)$ & $951(73.3)$ & \\
\hline \multirow[t]{2}{*}{ Alcohol consumption } & Yes & $19(2.7)$ & $23(4)$ & $42(3.3)$ & 0.208 \\
\hline & No & $694(97.3)$ & $554(96)$ & $1248(96.7)$ & \\
\hline \multirow[t]{2}{*}{ Regular Physical Activity } & Yes & $314(44)$ & $276(47.8)$ & $590(45.7)$ & 0.178 \\
\hline & No & $399(56)$ & $301(52.2)$ & $700(54.3)$ & \\
\hline \multirow[t]{3}{*}{ Type of Physical Activity } & Hard work & $151(21.2)$ & $78(13.5)$ & $229(17.8)$ & \multirow[t]{3}{*}{$0.001 * *$} \\
\hline & Moderate work & $300(42.1)$ & $247(42.8)$ & $547(42.4)$ & \\
\hline & Light Work & $262(36.7)$ & $252(43.7)$ & $514(39.8)$ & \\
\hline \multirow[t]{2}{*}{ BP problem } & Yes & $339(47.5)$ & $261(52.2)$ & $600(46.5)$ & 0.432 \\
\hline & No & $374(52.5)$ & $316(54.8)$ & $690(53.5)$ & \\
\hline
\end{tabular}

${ }^{a}$ Type-2 Diabetes Cases recruited in the Interventional study from community, ${ }^{b}$ Three Study districts i.e. Mehsana (Rural), Chota Udaipur (Tribal), Ahmedabad (Urban) in Gujarat State, ${ }^{\mathrm{c}}$ Baseline conducted in the year 2013, ${ }^{\mathrm{d}}$ Endline conducted in the year 2014.

Table 2. Knowledge level about Diabetes among Diabetic patients ${ }^{\mathrm{a}}$ with its interventions in three districts ${ }^{\mathrm{b}}$ of Gujarat, India.

\begin{tabular}{|c|c|c|c|c|}
\hline Knowledge Category & Knowledge Label & Baseline $^{c}(n=713) \%$ & Endline $^{d}(n=577) \%$ & $p$-Value \\
\hline \multirow[t]{6}{*}{ Causes } & Hormones & $13(1.8)$ & $14(2.7)$ & 0.332 \\
\hline & Obesity & $83(11.6)$ & $55(9.5)$ & 0.24 \\
\hline & Hereditary & $177(24.8)$ & $109(18.9)$ & $0.013^{*}$ \\
\hline & Sweet foods & $368(51.6)$ & $327(56.7)$ & 0.072 \\
\hline & Don't know & $200(28.1)$ & $139(24.1)$ & 0.112 \\
\hline & Other & $103(14.4)$ & $86(14.9)$ & 0.874 \\
\hline \multirow[t]{7}{*}{ Complications } & Eye & $270(37.9)$ & $269(46.6)$ & $0.002^{* *}$ \\
\hline & Heart & $140(19.6)$ & $86(14.9)$ & $0.027^{*}$ \\
\hline & Kidney & $141(19.8)$ & $81(14)$ & $0.007^{*}$ \\
\hline & BP problem & $219(30.7)$ & $120(20.8)$ & $0.000^{* * *}$ \\
\hline & Diabetic Foot & $94(13.2)$ & $88(15.3)$ & 0.297 \\
\hline & Don't know & $189(26.5)$ & $131(22.7)$ & 0.12 \\
\hline & Other & $195(27.3)$ & $88(15.3)$ & $0.000^{* * *}$ \\
\hline \multirow[t]{8}{*}{ Prevention } & By maintaining Weight & $356(49.9)$ & $325(56.3)$ & $0.025^{*}$ \\
\hline & By stopping Tobacco/Smoke & $217(30.4)$ & $160(27.7)$ & 0.296 \\
\hline & By regular food & $449(63)$ & $428(74.2)$ & $0.000 * * *$ \\
\hline & Avoid sweet food & $645(90.5)$ & $424(73.5)$ & $0.000^{* * *}$ \\
\hline & Avoid Fatty food & $338(47.4)$ & $150(26)$ & $0.000 * * *$ \\
\hline & Avoid fasting & $26(3.6)$ & $28(4.9)$ & 0.328 \\
\hline & Don't know & $37(5.2)$ & $1(0.2)$ & $0.000^{* * *}$ \\
\hline & Other & $137(19.2)$ & $15(2.6)$ & $0.000 * * *$ \\
\hline
\end{tabular}

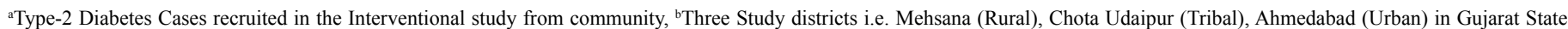
${ }^{\mathrm{c}}$ Baseline conducted in the year 2013, ${ }^{\mathrm{d}}$ Endline conducted in the year 2014. 
Table 3. Change in practices about Diabetes among Diabetic patients ${ }^{\mathrm{a}}$ with its interventions in three districts ${ }^{\mathrm{b}}$ of Gujarat, India.

\begin{tabular}{|c|c|c|c|c|}
\hline Practice Category & Practice Label & Baseline $^{c}(n=713) \%$ & Endline $^{d}(n=577) \%$ & $p$-Value \\
\hline \multirow[t]{4}{*}{ Investigations for $\mathrm{DM}$} & Private Laboratory & $563(79)$ & $375(65)$ & $0.000 * * *$ \\
\hline & Govt. Laboratory & $127(17.8)$ & $208(36)$ & $0.000 * * *$ \\
\hline & Trust Laboratory & $37(5.2)$ & $12(2.1)$ & $0.003 * *$ \\
\hline & No & $6(0.8)$ & $7(1.2)$ & 0.581 \\
\hline \multirow[t]{5}{*}{ Frequency of Blood/Urine Investigation } & Everyday & $6(0.8)$ & $7(1.2)$ & $0.000 * * *$ \\
\hline & Weekly & $35(4.9)$ & $15(2.6)$ & $0.000 * * *$ \\
\hline & Monthly & $474(66.5)$ & $166(28.8)$ & $0.000 * * *$ \\
\hline & 6 Months & $83(11.6)$ & $48(8.3)$ & $0.026^{*}$ \\
\hline & $>6$ Months & $115(16.1)$ & $341(59.1)$ & 0.258 \\
\hline \multirow[t]{5}{*}{ Medicines for DM } & Home Made & $42(5.9)$ & $9(1.6)$ & $0.000 * * *$ \\
\hline & From Medical Shop & $568(79.7)$ & $314(54.4)$ & $0.000 * * *$ \\
\hline & Traditional Healer & $6(0.8)$ & $5(0.9)$ & 0.99 \\
\hline & Private & $89(12.5)$ & $156(27)$ & $0.000 * * *$ \\
\hline & Government & $34(4.8)$ & $69(12)$ & $0.000 * * *$ \\
\hline \multirow[t]{5}{*}{ Type of Medicines } & Allopathic Tablet & $644(90.3)$ & $496(86)$ & $0.018^{*}$ \\
\hline & Allopathic Insulin & $67(9.4)$ & $30(5.2)$ & $0.006^{*}$ \\
\hline & Homeopathic & $4(0.6)$ & $2(0.3)$ & 0.697 \\
\hline & Ayurveda & $21(2.9)$ & $23(4)$ & 0.355 \\
\hline & Home Made & $29(4.1)$ & $12(2.1)$ & 0.054 \\
\hline \multirow[t]{2}{*}{ Regularity of Medicines } & Yes & $653(91.6)$ & $501(86.8)$ & $0.006^{*}$ \\
\hline & No & $60(8.4)$ & $76(13.2)$ & 0.325 \\
\hline \multirow[t]{2}{*}{ Regular Physical Activity } & Yes & $314(44)$ & $276(47.8)$ & 0.178 \\
\hline & No & $399(56)$ & $301(52.2)$ & 0.125 \\
\hline
\end{tabular}

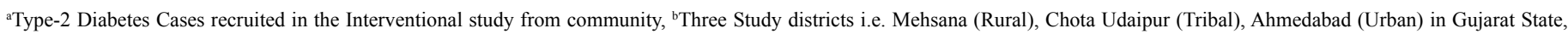
${ }^{\mathrm{c}}$ Baseline conducted in the year 2013, ${ }^{\mathrm{d}}$ Endline conducted in the year 2014.

is to document the change in knowledge level among diabetic cases with Behavior Change Communication (BCC) intervention. Even the changes in practices have been documented with the change of knowledge.

The strength of this study is unique in its design. Change in knowledge to practices and its documentation with community based intervention could reveal the mirror image of the prevention strategies of diabetes. In other word, this study covers diverse population such as rural, urban and tribal which is rare of its kind. However, the findings of this study could not be replicated to the global scenario, as the intervention has been planned to the regional perspective and might not be appropriate for the global picture.

\section{Conclusions}

This study found that the knowledge and practices about management of diabetes could be changed with suitable designed community based intervention programs. The background knowledge such as causes, symptoms, complications about type- 2 diabetes found to be significantly changed during endline evaluation from baseline.

\section{Conflict of interest}

The authors have declared that no competing interests exist.

\section{Author contribution}

Conception/design of the protocol- DS,SP,MP; Acquisition of data- SY,NT,DS,SP; data analysis/interpretation - SY, NT,DS; Drafting the first draft of the paper-SY,NT; Critically reviewing the paper and approval of final draft - all authors

\section{Acknowledgement}

We acknowledge project field staff and participants of this survey.
We also acknowledge the Department of Health, Government of Gujarat for support.

\section{Funding}

The Conquer Diabetes project leading to these results been funded by Bristol-Myers Squibb (BMS) Foundation. The funders did not have role in study design, data collection and analysis, decision to publish, or preparation of the manuscript.

\section{References}

1. World Health Organization. Global Status report on Non-communicable diseases 2014 Available from: http://www.who.int/nmh/publications/ncd-status-report-2014/en/ [Last accessed on July 2016].

2. Omiepirisa Yvonne Buowari (2013). Diabetes Mellitus in Developing countries and Case series, In "Diabetes Mellitus-Insights and Perspectives" Oluwafemi O. Oguntibeju Ed. InTech Open Publisher, Croatia, European Union. ISBN 978-953-51-0939-6.

3. Poornima S, Ragavendra L, Shivakumar KM (2012) Awareness regarding diabetes mellitus among degree college students of Mandya city, Karnataka, India. Indian J Prevention Soc Med 43: 283-287.

4. Radha V, Mohan V (2007) Genetic predisposition to type 2 diabetes among Asian Indians. Indian J Med Res 125: 259-274. [Crossref]

5. Kiberenge MW, Ndegwa ZM, Njenga EW, Muchemi EW (2010) Knowledge, attitude and practices related to diabetes among community members in four provinces in Kenya: a cross-sectional study. Pan Afr Med J7: 2. [Crossref]

6. Vankudre AJ, Padhyegurjar M, Gladius H, PadhyegurjarSB(2013) A study to asses awareness regarding diabetes mellitus and factors affecting it, in a tertiary care hospital in Kancheepurum district. Healthline4: 44-49.

7. Gulabani M, John M, Isaac R (2008) Knowledge of Diabetes, its Treatment and Complications Amongst Diabetic Patients in a Tertiary Care Hospital. Indian J Community Med33: 204-206. [Crossref]

8. Lemes Dos Santos PF, Dos Santos PR, Ferrari GS, Fonseca GA, Ferrari CK (2014) Knowledge of diabetes mellitus: does gender make a difference? Osong Public Health Res Perspect5: 199-203. [Crossref] 
9. Islam FM, Chakrabarti R, Dirani M, Islam MT, Ormsby G, et al. (2014) Knowledge, attitudes and practice of diabetes in rural Bangladesh: the Bangladesh Population based Diabetes and Eye Study (BPDES). PLoS One 9: e110368. [Crossref]

10. Gautam A, Bhatta DN,Aryal UR (2015) Diabetes related health knowledge, attitude and practice among diabetic patients in Nepal. BMC EndocrDisord 15:25. [Crossref]

11. Shah VN, Kamdar PK, Shah N (2009) Assessing the knowledge, attitudes and practice of type 2 diabetes among patients of Saurashtra region, Gujarat. Int J Diabetes Dev Ctries29: 118-122. [Crossref]

12. Sangra S, Nida N, Sachdev (2016) Knowledge, attitude and practice about type 2 diabetes mellitus in an adult population attending a primary health centre in rural Jammu. IOSR Journal of dental and medical sciences 15: 54-57.

13. Wild S, Roglic G, Green A, Sicree R, King H (2004) Global prevalence of diabetes: estimates for the year 2000 and projections for 2030. Diabetes Care27: 1047-1053. [Crossref]

14. Pradeepa R, Mohan V (2002) The changing scenario of the diabetes epidemic: implications for India. Indian J Med Res 116: 121-132. [Crossref]

15. Health Quality Ontario (2009) Behavioural interventions for type 2 diabetes: an evidence-based analysis. Ont Health Technol Assess Ser9: 1-45. [Crossref]

16. Ranking of Districts by Population Size, 2001 and 2011”. Census of India, 2011. Government of India. [Last accessed on 10 Aug 2016].
17. Directorate of Census Operations, Gujarat. Ministry of Home Affairs. Available from: http://censusgujarat.gov.in/ [Last accessed on Aug 2016].

18. Government of Gujarat. Official Gujarat State Portal, 2016. Available from: http:// www.gujaratindia.com/ [Last accessed on July 2016]

19. Yasobant S, Saxena D, Trivedi M, Gaurav K, Patel S, et al. (2016) Advocacy for a responsive health system to control diabetes: learning from western Indian state Gujarat, India. International Journal of Medical Science and Public Health 5: 1-5.

20. Sangra S, Nowreen N, Sachdev S (2016) Knowledge, Attitude and Practice about type 2 Diabetes Mellitus in an adult population attending a Primary Health Centre in rura Jammu. IOSR Journal of Dental and Medical Sciences 15: 54-57.

21. Mohan D, Raj D, Shanthirani CS, Datta M, Unwin NC, et al. (2005) Awareness an knowledge of diabetes in Chennai--the Chennai Urban Rural Epidemiology Study [CURES-9]. J Assoc Physicians India 53: 283-287. [Crossref]

22. Muninarayana C, Balachandra G, Hiremath SG, Iyengar K, Anil NS (2010) Prevalence and awareness regarding diabetes mellitus in rural Tamaka, Kolar. Int J Diabetes Dev Ctries30: 18-21. [Crossref]

23. Vankudre AJ, Padhyegurjar MS, Jennifer HG, Padhyegurjar SB (2013) A study to assess awareness regarding Diabetes Mellitus and factors affecting it, in a tertiary care hospital in Kancheepurum District. Healthline 4: 44-47.

Copyright: (2016 Yasobant S. This is an open-access article distributed under the terms of the Creative Commons Attribution License, which permits unrestricted use, distribution, and reproduction in any medium, provided the original author and source are credited. 